\title{
Targeted High-Throughput Glycoproteomics for Glyco-Biomarker Discovery
}

\author{
Eunju Choi ${ }^{1,2}$ and Michelle M. Hill ${ }^{1}$ \\ ${ }^{1}$ The University of Queensland Diamantina Institute, Brisbane, \\ ${ }^{2}$ The University of Queensland, School of Veterinary Science, Brisbane \\ Australia
}

\section{Introduction}

Biomarker discovery has become a major research area in proteomics as protein markers are more readily developed into clinical diagnostic tests than nucleic acid biomarkers. This is reflected by the fact that all United States Food and Drug Administration (US FDA)approved biomarkers currently available for clinical use are protein molecules (Srivastava, Verma, and Gopal-Srivastava 2005). Proteomic technologies for the global study of proteins have evolved in the past decade, in response to the growing demand for body fluid biomarker development (Anderson and Hunter 2006; Wang, Whiteaker, and Paulovich 2009). While mass spectrometry technology is improving in sensitivity and speed, several technical challenges in protein biomarker discovery still requires optimization. These include maximizing sample throughput to process adequate number of samples, reaching high sensitivity, specificity and reproducibility required for FDA approval, and managing the costs for biomarker discovery and assay development. This chapter will discuss the application of a targeted proteomics approach using lectins as affinity reagent throughout the biomarker discovery pipeline, and automation with magnetic beads to increase throughput.

\section{Biomarkers}

Biomarkers are biological molecules that correlate with a disease condition or phenotype. The search for cancer biomarkers has increased as the traditional tumor node metastases (TNM) system, a morphological pathology-based system used to determine the treatment strategy and prognosis in cancer patients, cannot correlate cancer subtypes with clinical outcomes (Ludwig and Weinstein 2005). Many studies using gene expression profiling have been published in the past decade contributing to a detailed molecular classification of each tumor subtype (Srivastava and Gopal-Srivastava 2002). Genomic profiling of tumor samples allowed the access to individualized genomic data to determine the appropriate treatment method or prognosis. For example, nonsmall cell lung cancer patients with mutated epidermal growth factor receptor (EGFR) will be able to receive an inhibitor of the EGFR tyrosine kinase activity called gefitinib (Belda-Iniesta, de Castro, and Perona 2011). The availability of specific non-invasive biomarkers will facilitate this type of tailored or personalized medicine to improve therapy and patient outcomes. 


\subsection{Types of biomarkers}

Biomarkers can be divided into types based on clinical significance; including predictive, detection, diagnostic and prognostic markers (Mishra and Verma 2010). Predictive markers or response markers are used to assess the response of a specific drug to allow selection of appropriate treatment regimes for each patient. For example, in breast cancer patients, Her2/Neu overexpression will lead to treatment using Herceptin ${ }^{\circledR}$, whereas for other types of breast cancer, tamoxifen provides the best patient outcomes (Hudis 2007). Thus, Her2/Neu is a predictive cancer biomarker for some breast cancer therapies (Roses et al. 2009). Likewise, drugs such as INGN 201 (ADVEXIN®), which targets abnormal p53 tumor suppressor function, can be administered as monotherapy or in combination with radiation and/or chemotherapeutic agents in cancers showing abnormal p53 function (Gabrilovich 2006). Pharmacodynamic markers are used to select the appropriate dose of chemotherapeutic drugs. These markers help in optimizing cancer drug doses to minimize cytotoxicity and are often used in clinical trials. Mitogen-activated protein kinase (MAPK), Akt, or p27 which are downstream receptor-dependent molecules of phosphorylated EGFR are pharmacodynamic biomarkers for certain EGFR tyrosine kinase inhibitors (Albanell, Rojo, and Baselga 2001). Diagnostic markers can be used for early detection, determination of stage, tissue or relapse (Verma and Manne 2006). For example, the presence of bladder tumor antigen (BTA) and nuclear matrix protein-22 (NMP-22) in urine indicates the presence of bladder cancer (Lau et al. 2009) and serum alpha-fetoprotein is useful to diagnose nonseminomatous testicular cancer (Sturgeon et al. 2008). Prognostic biomarkers are used to discriminate benign from malignant tumors. For example, human papillomavirus (HPV) associated in oral cancer has a better survival time compared to other types of oral cancer (Mishra et al. 2006). Commercially available tests based on the genetic expression of the virus can be used to determine the prognosis. Some biomarkers can have overlapping uses, i.e. carcinoembryonic antigen (CEA) is used as a prognostic and diagnostic marker and so can be used in postoperative surveillance and monitoring of the effectiveness of therapy in advanced colorectal cancer (Sturgeon et al. 2008).

Biomarkers can be based on any biomolecule including DNA, RNA, protein, and carbohydrate markers (Mishra and Verma 2010). Single nucleotide polymorphisms (SNP), loss of heterozygosity, copy number variants, chromosomal aberrations such as microsatellite instability and epigenetic modifications, and mutations in oncogenes or tumor suppressor genes are all examples of DNA markers (Ludwig and Weinstein 2005). RNA markers are usually identified from microarray analysis, and can be validated using qRTPCR (Gray and Collins 2000). The potential of microRNAs (miRNA) or small non-coding RNAs for use as cancer biomarkers has also been documented (Bartels and Tsongalis 2009). DNA and RNA markers have improved the molecular characterization of specific tumors and their subtypes, but the practical usefulness in the clinical setting may be limited as the tests involve intensive processing, and are far from being noninvasive, simple and cost effective. Protein biomarkers are clinically useful because cancer cells secrete or shed proteins and peptides into body fluids, allowing minimally invasive tests. Hence mass spectrometry based proteomics techniques have evolved with a purpose driven aim to discover novel protein biomarkers.

\subsection{Biomarker discovery}

Ideal biomarker tests should be noninvasive, cheap, simple to perform, informative and accurate (Boja et al. 2011; Negm, Verma, and Srivastava 2002; Srivastava and Gopal- 
Srivastava 2002). The process of developing such a test is a difficult and uncertain task, as reflected by the declining number of newly approved biomarker tests by the FDA. However, despite this, there are a growing number of articles published on potential biomarker candidates (Anderson and Anderson 2002; Polanski and Anderson 2007; Rifai, Gillette, and Carr 2006). Depending on the purpose of the biomarker and its application in clinics, the criteria and developmental approach for each biomarker varies. The conventional biomarker discovery pipeline involves five stages. Clearly defined issues should be addressed at each stage to guide the process through to success (Fig. 1) (Surinova et al. 2011; Pepe et al. 2001).
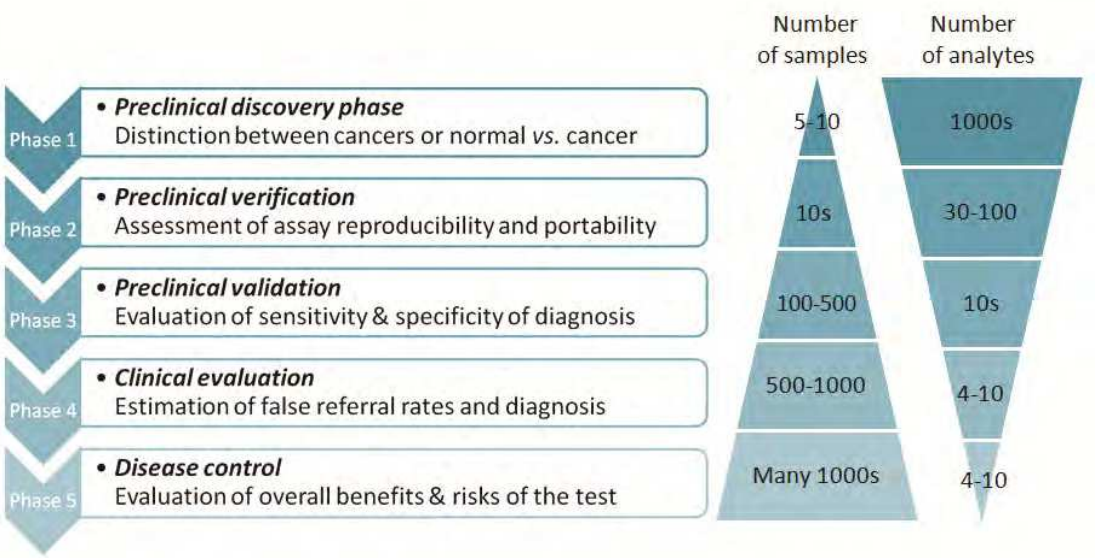

Fig. 1. Biomarker discovery workflow and study objectives for each phase. Modified from Pepe et al. (Pepe et al. 2001)

Phase 1 - Preclinical Discovery phase. Phase 1 is dedicated to hypothesis driven identification of candidate biomarkers, ranking and/or finding suitable combinations of potential biomarkers. The clinical question is defined and a small number of samples are obtained and analyzed to generate a list of candidates with their fold changes (Pepe et al. 2001).

Phase 2 - Preclinical verification. Phase 2 evaluates the (ranked) list of potential biomarkers generated in phase 1 using clinical samples from cases with known diagnosis. The end point of the assay may be mean concentration of candidate protein(s) or a unique signature associated with either one of the groups (Alonzo, Pepe, and Moskowitz 2002). The reproducibility, dynamic range and limit of detection (sensitivity) are determined in a relatively small cohort of patients, but with more patients than phase 1 (Rifai, Gillette, and Carr 2006). Another aim of the verification phase is to determine the sample size required for the Preclinical validation phase, to achieve statistical significance.

Phase 3 - Preclinical validation. The third phase is still within the scope of preclinical assessment but the aim is to generate a disease signature to determine whether the study objective can be met by the platform. The control and patient groups are designed retrospectively and the numbers used depend on the sensitivity and specificity of the biomarker determined in the previous phase, and the prevalence of the cancer in the population. The results are evaluated for analytical performance including test accuracy and precision, and clinical performance (Gutman and Kessler 2006), which must meet single- 
digit measurement coefficient-of-variation values $(\mathrm{CVs})$ from measurement of thousands of patient samples. If the performance of the optimized assay meets the clinical objective, the process proceeds to the next phase, clinical evaluation.

Phase 4 - Clinical evaluation. Phase 4 is the development of a clinical assay and clinical evaluation of the biomarker as an in vitro diagnostic test. This phase is prospective and involves new control subjects and patients who are yet to be diagnosed (Manolio, BaileyWilson, and Collins 2006). The patient group sizes increase again based on the results from phase 3 . The aim of phase 4 is to fulfil the clinical requirements and determine the true positive and false positive rates.

Phase 5 - Disease control. The last phase aims to determine the effect of the biomarker on disease management in the target population. Therefore, the biomarker proceeds into phase 5 when it is approved and accepted for clinical use. Phase 5 consists of the largest sample size and thus takes many years to complete. Data pertaining to cost of the test, as well as the consequences from the use of the biomarker are determined.

Biomarker development has had limited progress due to the lack of effective technology, established guidelines for designing clinical sample groups in each phase, standardized procedures for the development of the biomarker pipeline and quality assessment of the studies published (Mischak et al. 2007; Surinova et al. 2011). Therefore, by addressing the study objective clearly and by applying considerations for each phase, biomarker research should lead to more translatable candidates in the clinical context.

\section{Proteomics for biomarker discovery}

As described above, the road to discover biomarkers is a long and uncertain path consisting of different stages and multiple validation steps. The decisions made especially in the first few phases on the ranking of candidates or the best combination of candidates to maximize the sensitivity and specificity have enormous effects on the outcome of a successful biomarker assay. Consistency in the proteomics techniques and sample type used for each phase is crucial to successful biomarker discovery and validation.

\subsection{Choice of sample type}

The choice of sample type may be determined by availability, as well as complexity of the sample type for the available technology. Although the final preferred outcome are body fluid (commonly blood) tests, plasma or serum as a sample for proteomics is technically challenging due to dilution of potential biomarkers and the presence of high abundance proteins masking the lower abundance disease-associated proteins. Estimates suggest that there are more than $10^{6}$ proteins in the blood proteome while one protein (albumin) accounts for more than half of all blood proteins (Zhang, Faca, and Hanash 2011). Approximately 22 proteins, including globulins, transferrins and fibrinogen make up $99 \%$ of the total blood proteins. Additionally, the concentration of a blood protein can range from less than $1-5 \mathrm{pg} / \mathrm{ml}$ to more than 55 billion $\mathrm{pg} / \mathrm{ml}$, stretching across seven logs (Zhang, Faca, and Hanash 2011).

Immunodepletion columns have been developed to remove the top 6, 7, 12, 14, or 20 proteins from plasma/serum, prior to proteome profiling (Smith et al. 2011; Gong et al. 2006; Tu et al. 2010). However, this procedure may also deplete potential proteins of interest that are bound to albumin in the blood stream, as well as low abundance proteins due to non-specific binding (Gong et al. 2006). Due to these technical difficulties, many studies 
choose to use tissue samples in the discovery phase; however, it is difficult to predict which proteins will be easily detected in the blood as data derived from tissue is not always translatable to blood (Abbott and Pierce 2010). Therefore, direct analysis of plasma or serum rather than tissue may be useful in the initial discovery phase (Rifai, Gillette, and Carr 2006; Kulasingam and Diamandis 2008).

\subsection{Choice of technology}

Ideally, similar or compatible techniques are used throughout the biomarker discovery and validation pipeline. However, no single technique can fulfill the requirements of all 5 phases with sufficient throughput, sensitivity and accuracy. Phase 1 requires the measurement of thousands of analytes in few samples, while phases 2-4 require the (simultaneous) measurements of fewer analytes in increasing number of samples. Furthermore, clinical assays (phase 4-5) ideally requires minimal sample handling.

Current proteomic profiling methods used in the discovery phase are not suitable for later phases since techniques such as two-dimensional difference gel electrophoresis (2D-DIGE) and multidimensional protein identification technology (MuDPIT) can only analyze one sample at a time, and require days of processing. Current technologies for preclinical and clinical phases such as radioimmunoassay (RIA), enzyme-linked immunosorbent assay (ELISA) and multiplex fluorescent detection technology are antibody-based assays requiring identified target, and hence not applicable to the discovery phase. The development and use of Selected Reaction Monitoring mass spectrometry (SRM-MS) as pre-clinical and potentially clinical assays not only provide a link between discovery, validation and clinical techniques, it also avoids the significant cost outlay for antibody development. Hence SRMMS technology is fast becoming the method of choice for pre-clinical phases, and is set to make it into the clinical arena.

\subsection{Improving throughput}

Due to the high cost and low sample throughput in proteomics technology, biomarker discovery workflows have commonly suffered from the lack of sufficient technical and biological replicates. To address these short-comings, significant effort has been spent on sample preparation and separation using automation on robotic liquid handler, and the introduction of nanomaterial for nanoproteomics (Ray et al. 2011). Increased throughput in mass spectrometry can be achieved by means of multiplexing samples (Boersema et al. 2009; Chen et al. 2007) and/or shortening bioinformatic analysis time after the generation of mass spectrometry data (Martens 2011a, 2011b).

\subsection{Targeted proteomics}

Discovery proteomics workflows generally require multiple steps of separation due to high sample complexity. One strategy to reduce extensive separation steps is to enrich for a subset of proteins that are disease-relevant. In this chapter, we focus on the potential of targeted glycoproteomics as an all-encompassing technology for the phases of (glyco-) biomarker discovery.

\section{Glycoproteomics}

Glycoproteomics, an area of proteomics with biological and clinical significance, is an emerging field in biomarker research (Pan et al. 2011; Meany and Chan 2011). 
Glycoproteins are a group of proteins in which one or more glycans (sugars) are covalently bonded to the protein through a process called glycosylation. There are two main types of protein glycosylation: (i) N-linked glycosylation whereby the glycan is attached to the amide nitrogen of asparagine in a consensus Asparagine- $X$-Serine/Threonine (Asp-XSer/Thr) sequence, where $X$ can be any amino acid except proline and (ii) O-linked glycosylation in which the glycan is attached to the hydroxyl oxygen of serine or threonine in the protein. Glycosylation is the most abundant posttranslational modification and the most structurally diverse. There are at least 14 different monosaccharides and 8 different amino acids involved in this process with at least 41 different chemical bonds in glycanprotein linkage.

Glycoproteins are important targets in the search for biomarkers for the following reasons: (i) more than $50 \%$ of secreted proteins are glycoproteins, (ii) glycosylation changes in tissues, blood and serum from patients with disease has been implicated in pathogenesis, (iii) changes in glycosylation can be more distinctive than changes in protein expression, as specific glycan structures are generally not present normally, but increase in disease states, (iv) changes in glycosylation occur in many proteins including abundant proteins, thus increasing the likelihood of early detection, (v) the glycosylated form of a particular protein site is generally stable for a given cell type and physiological state, and (vi) as one of the important functions of glycans is in cell-cell interactions and consequently the control of cell function, alterations of protein glycosylation can be diagnostic for a disease (Pan et al. 2011; Packer et al. 2008). Altered glycosylation can be seen in diseases as hypo, hyper or newly glycosylated sites, and/or altered carbohydrate moieties (Pan et al. 2011).

Although advances in technologies used in glycoprotein research has been slow due to the complicated nature and vast variety of changes in glycosylation, advances in proteomic technologies have facilitated glycoproteomics research. An excellent example of a glycobiomarker is alpha-fetoprotein (AFP), a marker for hepatocellular carcinoma (HCC) (Sturgeon et al. 2010). The specificity for AFP in HCC is low, limiting the use in the clinic (Meany, Sokoll, and Chan 2009), however, recent studies have shown that the fucosylated form of AFP which is highly reactive with the Lens culinaris agglutinin, also known as AFPL3, improves the specificity (Masuda and Miyoshi 2011), demonstrating the utility of glycobiomarkers.

\subsection{Glycoproteomic approaches for biomarker discovery}

A typical glycoproteomics pipeline consists of glycoprotein enrichment techniques, followed by multidimensional chromatographic separation, and mass spectrometry with bioinformatic data analysis. Glycoproteomics approaches can be divided into glycoproteinbased and glycopeptide-based methods (Fig. 2). Glycoprotein-based enrichment methods, also known as the top-down workflow, enrich for the glycoproteins prior to proteolytic digestion with enzymes such as trypsin. Glycan cleavage is performed before or after proteolytic digestion. In glycopeptide enrichment methods, proteolytic digestion is performed before enrichment. This is also known as the bottom-up workflow. The bottomup workflow is more popular as it provides detailed information of a glycoprotein profile, and also specific mapping of glycosylation sites. However, the bottom-up workflow can result in very low sample throughput, and current technology is not capable of determining detailed glycan structure of glycoproteins in one analysis (Pan et al. 2011). On the other hand, the top-down workflow may not accurately provide mapping of glycosylation sites, 


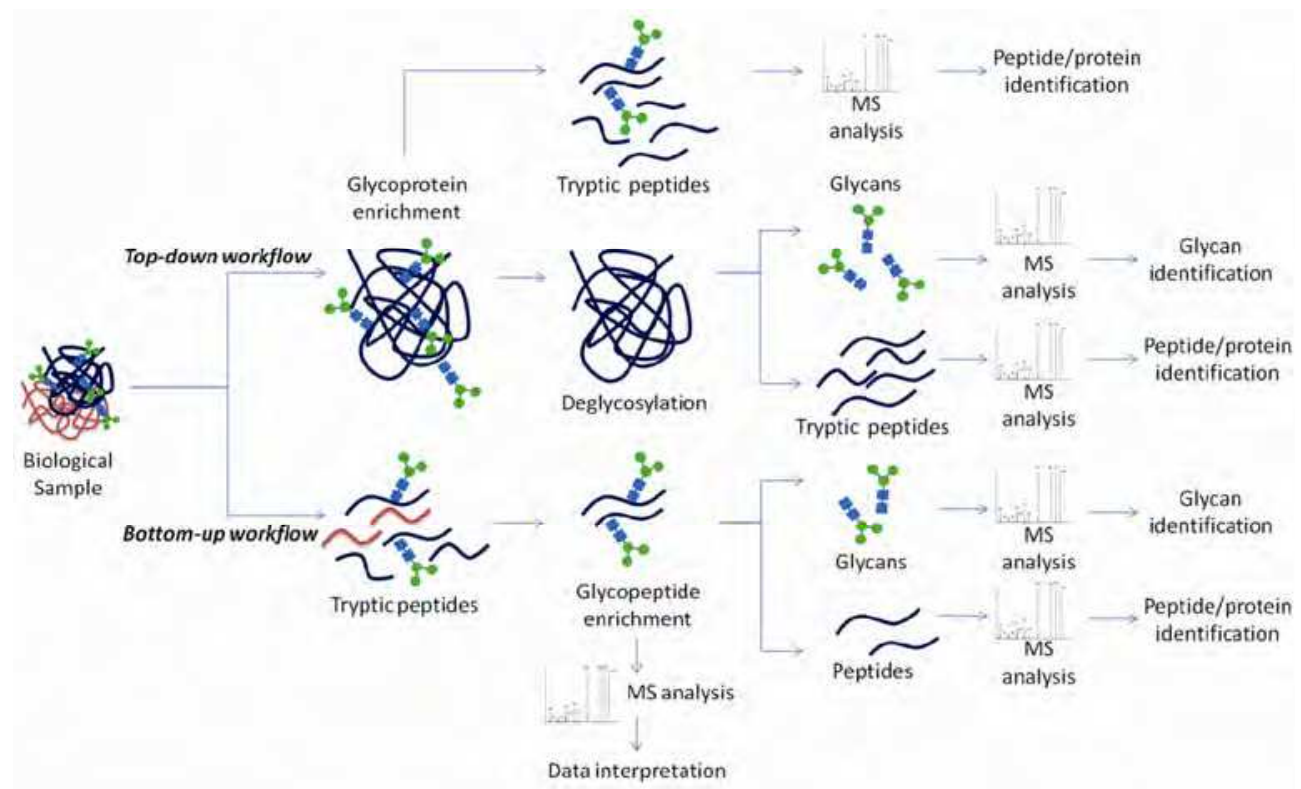

Fig. 2. Glycoproteomic approaches for glycan, deglycosylated and intact glycopeptide analysis. In the top-down workflow, glycoprotein enrichment is performed which may or may not follow deglycosylation. In the bottom-up workflow, proteins are digested then glycopeptides are enriched for further analysis.

although it results in greater glycoprotein sequence coverage. Therefore, the technique used will depend on the specific research question asked.

\subsection{Glycoproteome enrichment techniques}

Several techniques have been used for enrichment of glycans, glycopeptides and glycoproteins (Tousi, Hancock, and Hincapie 2011; Rakus and Mahal 2011; Pan et al. 2011), including hydrazide chemistry-based solid phase extraction methods, boronic acid-based solid phase extraction, size exclusion chromatography, hydrophilic interaction liquid chromatography (HILIC), activated graphitized carbon and lectin affinity based methods (Table 1). This chapter will discuss the potential of lectins as a universal enrichment tool in all phases of the glyco-biomarker discovery workflow. Lectins are naturally occurring sugar binding proteins which are highly specific for their sugar moieties. Their abilities to recognize and bind to specific glycans make them ideal for glycan structure specific glycoprotein enrichment. Lectins have been used in biological research as an affinity reagent for the past few decades, with applications such as lectin histochemistry (Brooks et al. 1996; Carter and Brooks 2006), lectin blotting (Welinder et al. 2009), lectin-affinity chromatography in combination with mass spectrometry (Abbott and Pierce 2010; Yang et al. 2006; Zhao et al. 2006; Xu et al. 2007; Qiu et al. 2008; Jung, Cho, and Regnier 2009) and lectin microarray (Gupta, Surolia, and Sampathkumar 2010; Katrlik et al. 2010) to examine the glycoproteome of serum and plasma. 


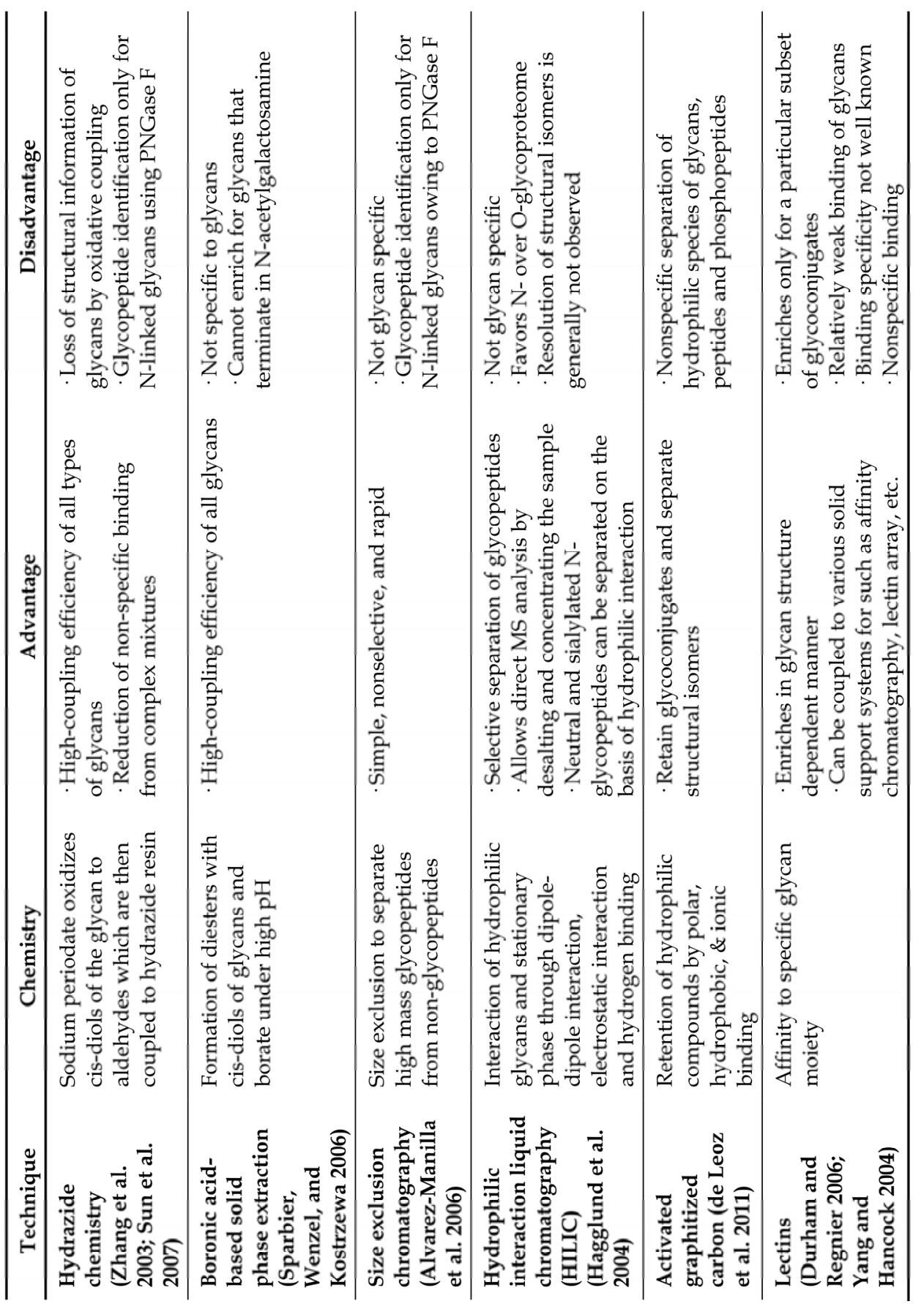

Table 1. Glycoproteome enrichment techniques 


\section{Use of lectins in glyco-biomarker discovery}

The potential of a lectin-enrichment step to be coupled to different downstream assay techniques is attractive in glyco-biomarker discovery as it reduces the potential variation introduced by the change of enrichment methods going from one phase to another (Fig. 3). For example, in the discovery workflow of phase 1, lectin-enrichment can be followed by glycoprotein or glycopeptide separation and identification by tandem mass spectrometry (MS/MS), to measure hundreds of analytes. In the preclinical stages (phases 2 and 3), lectin affinity isolation may be coupled to SRM-MS for targeted quantification of a reduced number of candidates. Although SRM-MS assays may have the desired sensitivity and reproducibility, routine use in clinical pathology laboratories will need additional technology optimization. Lectin affinity can also be incorporated into other preclinical verification technology such as multiplexed immunoassay incorporating fluorescencelabeled microspheres with specific antibodies (Li et al. 2011), multiplexed protein analysis using antibody-conjugated microbead arrays (Theilacker et al. 2011), and multiplex proteins assays using magnetic nanotag sensing (Osterfeld et al. 2008). For clinical phases 3-5, existing antibodies may be used or antibodies may be developed for use in lectin microarrays or lectin-immunosorbent assays.
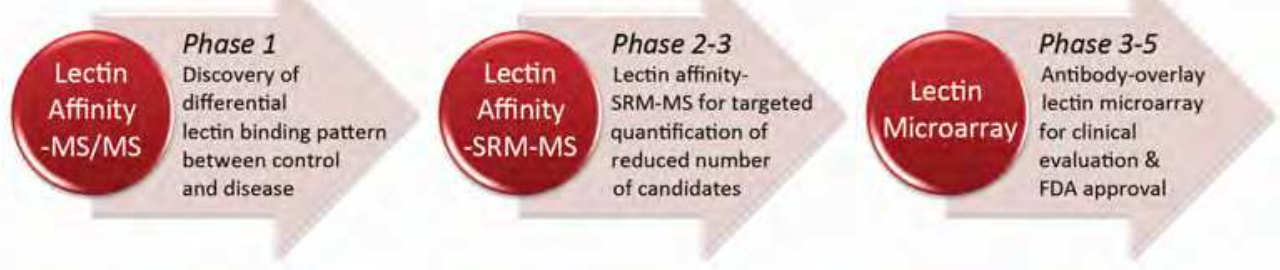

Fig. 3. Biomarker discovery pipeline using lectins.

\subsection{Lectin affinity chromatography for glyco-biomarker discovery}

Lectin affinity chromatography is a technique that employs one or more lectins to enrich for structurally similar subset(s) of glycoproteins or glycopeptides (Jung, Cho, and Regnier 2009; Durham and Regnier 2006; Yang et al. 2006). By coupling this technique to mass spectrometry analysis, bound and unbound fractions can be analysed to identify proteins in the two fractions. Lectin affinity chromatography can be performed in different formats including tubes, packed columns, microfluidic channels and high pressure liquid chromatography (HPLC) (Mechref, Madera, and Novotny 2008). Different types of support matrices can be used to immobilize the lectins, such as sepharose/agarose beads (Kobata and Endo 1992; Mechref, Madera, and Novotny 2008), magnetic beads (Lin et al. 2008), silica or styrene-divinylbenzene co-polymers coated with a cross-linked polyhydroxylated polymer (POROS) (Tousi, Hancock, and Hincapie 2011). Commonly used lectins include mannose and glucose binding concanavalin A (ConA) and $\mathrm{N}$-acetylglucosamine binding wheat germ agglutinin (WGA) for their broad binding specificities and affinity to most Nlinked glycans in biological material. For O-linked glycans, jacalin (JAC) is added to these two lectins for a global range of glycoprotein enrichment. For more specific enrichment, sialic acid and/or fucose binding lectins can be used, such as Sambucus nigra agglutinin 
(SNA) and Maackia amurensis agglutinin (MAA) for sialic acid and Aleuria aurantia lectin (AAL) for fucose. A wide range of different sample types have been used including soluble and membrane derived glycoconjugates from serum/plasma, cell lysates and tissue homogenates. Elution of bound glycoproteins/peptides is commonly achieved using competitive sugar of relatively low concentrations (5-100 mM) (West and Goldring 1996) or low $\mathrm{pH}$ such as acidic solutions (Green, Brodbeck, and Baenziger 1987).

Lectin affinity chromatography can be incorporated into top down or bottom up proteomics workflows, where the glycoproteins or the glycopeptides are identified by LC-MS/MS, respectively. Top down workflows identify lectin-reactive glycoproteins primarily by the non-glycosylated peptides in the isolated glycoproteins. The advantages are high sensitivity and ease of use, but the top down approach does not identify the actual glycopeptide(s) that bound to the lectins. Bottom up workflows directly identify the captured glycopeptides, but is technically more challenging due to the lower amount of targets. Top down and bottom up approaches generate complementary data and have both been successfully applied in glyco-biomarker discovery (see 5.1.2).

Modified versions of lectin affinity chromatography has been reported including Serial Lectin Affinity Chromatography (S-LAC) which uses a series of sequential lectin affinity steps (Durham and Regnier 2006) or Multi-lectin Affinity Chromatography (M-LAC) which combines 3 or more different lectins for one-step isolation (Yang and Hancock 2004; Ahn et al. 2010; Na et al. 2009). Both methods can be incorporated into the top down and bottom up workflow. However, the bottom up workflow is preferred for S-LAC as proteins with more than 1 glycosylation site with binding affinity to both lectin, may not be identified by the second lectin. S-LAC using ConA and JAC was shown to be efficient for enriching O-linked glycopeptides, since ConA removes most N-linked glycopeptides containing mannose which will facilitate the binding of O-linked glycopeptides to Jacalin (Durham and Regnier 2006). M-LAC is also an effective system to simplify complex samples allowing enrichment of approximately $50 \%$ of the plasma proteome in one-step (Dayarathna, Hancock, and Hincapie 2008). The bound fraction of M-LAC using ConA, WGA and JAC has been used by Zeng and others for the initial identification of candidate biomarkers in serum from breast cancer patients (Zeng et al. 2011). M-LAC was coupled with 1D SDS-PAGE, isoelectric focusing and lectin-overlay antibody microarray to identify several glycoproteins such as alpha-1B-glycoprotein and complement C3 as potential candidates (Zeng et al. 2011). Kullolli et al. further developed M-LAC into a high performance multi-lectin affinity chromatography (HP-MLAC), involving targeted albumin and immunoglobulin depletion in-line with glycoprotein affinity isolation using M-LAC (Kullolli, Hancock, and Hincapie 2010). This method has shown reproducibility and consistency of the bound and unbound fraction over 200 runs which promises to provide quality plasma glycoproteome data for clinical proteomics.

\subsubsection{Technical aspects of lectin affinity enrichment}

Although widely used, significant binding of non-glycosylated proteins during lectin affinity enrichment has been reported (Lee et al. 2009). Potential causes of the non-specific binding include the presence of protein complexes and prolonged incubation leading to non-specific binding to support beads. To optimize binding conditions, we investigated glycoprotein capture using Concanavalin A (ConA)-magnetic beads with a range of mild to stringent binding buffers, using a short incubation time of 30 minutes (Loo, Jones, and Hill 2010). In order to disrupt protein-protein complexes which may result in binding of non- 
glycosylated proteins to lectin beads, we included a reducing agent ( $1 \mathrm{mM}$ DTT) and a strong detergent $(0.2 \%$ SDS) in the binding and washing steps. Although this resulted in $\sim 20 \%$ loss of protein binding compared to previous lectin-affinity buffer (Yang et al. 2006), we still observed strong affinity between lectin and their cognate glycans (Loo, Jones, and Hill 2010). Using the most stringent buffer condition, we have shown reproducibility of lectin-glycoprotein binding, confirming this buffer condition helps to avoid non-specific binding of lectins while enriching for glycoproteins with the highest affinity to the individual lectins (Loo, Jones, and Hill 2010).

\subsubsection{Application of lectin affinity enrichment in biomarker discovery}

Top down workflows that incorporate lectin affinity chromatography have been used to identify potential biomarkers in diseases including psoriasis (Plavina et al. 2007), hepatocellular carcinoma ( $\mathrm{Na}$ et al. 2009), diabetic nephropathy (Ahn et al. 2010) and bladder cancer (Yang et al. 2011). Plavina et al. depleted the two most abundant plasma proteins, albumin and immunoglobulin, and performed M-LAC consisting of ConA, WGA and JAC to identify numerous tissue leakage proteins present in plasma at low $\mathrm{ng} / \mathrm{mL}$ concentrations, such as galectin-binding protein 3, which was subsequently verified by ELISA (Plavina et al. 2007). Na et al. used M-LAC consisting of ConA, WGA, JAC, SNA, and AAL and 2D-DIGE with liver tissue samples to identify human plasma carboxylesterase 1 as a potential biomarker for hepatocellular carcinoma (Na et al. 2009). Ahn et al. used M-LAC to capture plasma glycoproteins and found 13 up-regulated and 14 down-regulated glycoproteins in diabetic nephropathy (Ahn et al. 2010). Yang et al. used ConA and WGA for dual-lectin affinity chromatography to enrich for glycoproteins in urine to identify biomarker candidates for bladder cancer and identified 265 glycoproteins with higher abundance in the cancer group compared to the control group (Yang et al. 2011). While there was an overlap of the proteins identified, 240 glycoproteins were uniquely identified by each of the methods. Furthermore, lectin affinity chromatography of glycoproteins has been used for a cell cycle study which combined MAA-affinity chromatography of glycoproteins from cell lysates of the cervical cancer cell line, HeLa cells, and periodate labeling of membrane proteins of intact cells coupled to hydrazide chemistry, to identify distinct expression patterns during the cell cycle which demonstrated a 4-fold change in membrane protein expression during different cell cycles (McDonald et al. 2009).

Bottom up lectin-affinity has also been successfully applied in glyco-biomarker discovery. For example, Drake et al. utilized immunoaffinity depletion and subsequent M-LAC with SNA and AAL to identify 122 human plasma glycoproteins with 247 unique glycosites (Drake et al. 2011). Alvarez-Manilla et al. used ConA-sepharose to identify 18 glycoproteins unique to mouse embryonic stem cells and 45 proteins exclusively found in cells of differentiated embryoid bodies (Alvarez-Manilla et al. 2010). Furthermore, the bottom up method coupled with filter-aided sample preparation (FASP) was shown to detect $6367 \mathrm{~N}$ glycosites on 2352 proteins which accounts for $74 \%$ of known mouse N-glycosites and 5753 unique sites in four mouse tissues and blood plasma, demonstrating the ability of lectin affinity chromatography techniques to enrich for glycopeptides (Zielinska et al. 2010).

\subsection{Lectin magnetic bead array for high-throughput glyco-biomarker discovery and preclinical verification}

Differential binding to a panel of lectins (a lectin signature) can be used as disease biomarker. This is the principle behind lectin microarrays (see section 5.3) for known target 
proteins, however, there is a lack of high-throughput methodology for de novo discovery of lectin signatures for potential glyco-biomarkers. To this end, we introduced the concept of a high-throughput lectin-magnetic bead array (LeMBA), consisting of a panel of individual lectin-magnetic beads arrayed in a microplate (Loo, Jones, and Hill 2010). The use of magnetic beads allows liquid handler-assisted automation to increase the throughput while assessing individual lectin-binding sub-glycoproteomes. Direct coupling to LC-MS/MS for glyco-protein (top down) or glyco-peptide (bottom up) analysis enables the simultaneous identification of glyco-biomarker and its lectin signature.

While most (glyco-)biomarker discovery workflows focus on low abundance proteins in the serum/plasma, LeMBA-MS screens for specific glycan structure changes by determining the lectin signatures of the glyco-proteome. Hence, instead of identifying new, low abundance proteins secreted or leaked by the diseased cells, the LeMBA approach focuses on alteration in the glycosylation structure of medium- to highabundance secreted proteins. Since altered glycosylation of secreted and/or cell surface proteins reflects cell function and hence disease progression (Pan et al. 2011; Packer et al. 2008), this approach is likely to discover disease-relevant glyco-biomarkers. Previous studies aimed to find glyco-biomarkers have identified high abundance proteins in the blood as potential biomarker candidates, such as haptoglobin (Yoon et al. 2010; Fujimura et al. 2008), hemopexin (Comunale et al. 2009), transferrin (Zeng et al. 2011; Bones et al. 2010) and alpha-1B-glycoprotein (Zeng et al. 2011).

LeMBA results will be trading low abundance for high specificity as glycosylation changes detected by multiple lectins will be unique for the altered glycan structure. This approach also holds promise for early diagnostic biomarkers since detection of low abundance early diagnostic markers is extremely difficult to achieve with any throughput using the current detection systems and workflows. If glycosylation changes are identified in early stages of diseases in medium to high abundance proteins, these changes can be developed into biomarkers with reasonable sensitivity and specificity as the proteins carrying the altered glycan will be easy to detect.

Taken together, it is expected that candidate biomarkers resulting from LeMBA-MS screen will increase the sensitivity and specificity of glyco-biomarker, owing to the ability of lectin signatures to identify overall and subtle changes. For biomarker discovery phase 2, combinations of lectin signatures that show the biggest changes between normal and disease will result in a panel of potential biomarker candidates that can be verified using LeMBA coupled to SRM-MS for verification and antibody-overlay lectin microarrays for further validation (Boja and Rodriguez 2011).

\subsection{Lectin microarray as high-throughput glyco-biomarker validation assay}

Since their introduction in 2005, lectin microarrays have emerged as a new technology that utilizes lectins as a glyco-profiling tool. A typical microarray contains 6 to 43 lectins immobilized on a solid surface and binding of glycoproteins to lectins is, in most cases, detected by standard fluorescence microarray scanners (Gemeiner et al. 2009). Lectin microarrays are a rapid, sensitive and high-throughput screening tool, highly suitable for all phases of glyco-biomarker discovery, depending on the type used.

\subsubsection{Types of lectin microarrays and their use in biomarker discovery}

Generally, there are two types of lectin microarrays: the direct assay and reverse-phase dotblot lectin array (Gemeiner et al. 2009; Gupta, Surolia, and Sampathkumar 2010). The direct 
assay format immobilizes lectins on a solid surface and applies prelabeled sample over the surface. On the other hand, reverse-phase dot-blot lectin array immobilizes glycoproteins on a solid surface and applies prelabeled lectins. These two types have been used for biomarker discovery phase 1 for pancreatic cancer ( $\mathrm{Li}$ et al. 2009; Patwa et al. 2006; Liu et al. 2010), glioblastoma (He et al. 2010), HCC (Zhao et al. 2007) and colorectal cancer (Qiu et al. 2008) to investigate differential glycosylation between control and disease.

The direct assay can also be modified into a sandwich assay called the antibody-overlay lectin microarray (ALM) or lectin-overlay antibody microarray (LAM). In ALM, lectins are immobilized on a solid surface; glycoproteins are added, followed by a biotinylated antibody overlay that binds to the protein. Then, streptavidin with a fluorophore attached is added, and the fluorescence is detected. The difference between ALM and LAM is that in LAM, the antibody is attached to a solid surface and biotinylated lectins are overlaid to bind to the glycan structure (Fig. 4). These types of lectin microarrays may be used for biomarker discovery phase 3 and higher and can be developed into clinical assays with a condition that they are reproducible with less than $10 \%$ CV (Fung 2010).

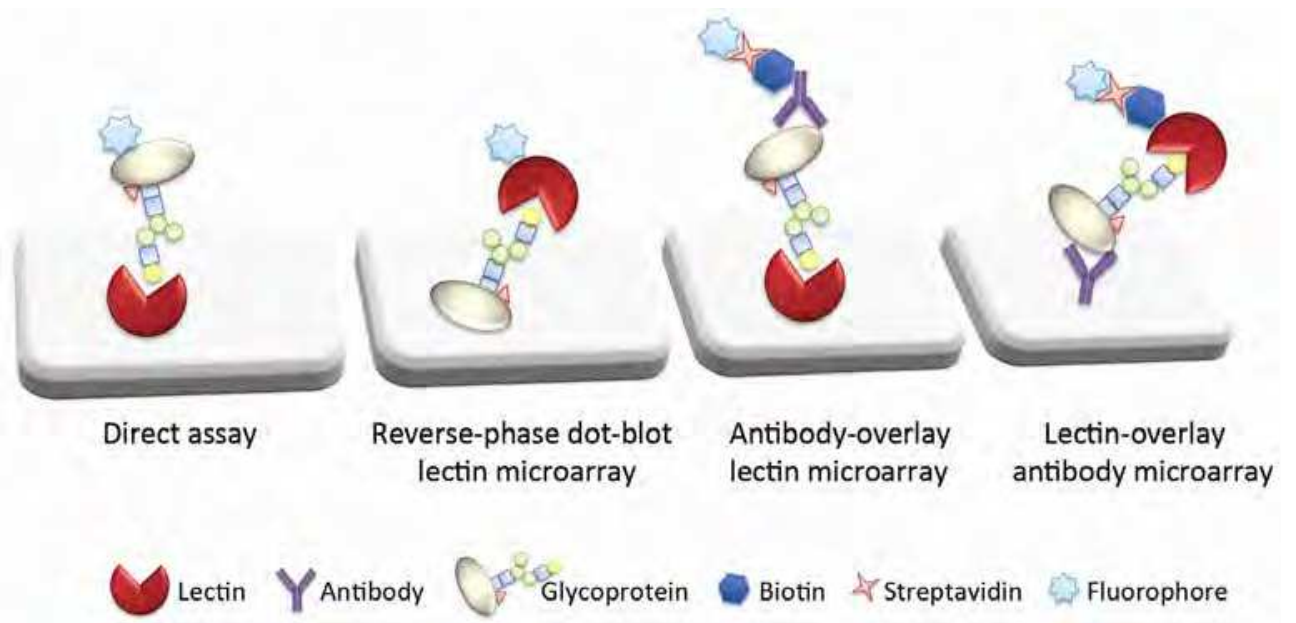

Fig. 4. Different types of lectin microarrays.

\subsubsection{Technological aspects of lectin microarrays for phase 3 and above biomarker assay development}

Preserving the carbohydrate recognition domain (CRD) is important for the reproducibility of the assay for assays with immobilized lectins. Popular methods of lectin immobilization include adsorption on nitrocellulose, attachment of amine functional group of protein backbone of lectins to a solid surface through epoxy- or N-hydroxysuccinimidyl-derived ester coated glass slides (Kuno et al. 2005) and use of self-assembled monolayers of thiols on gold-coated surfaces (Zheng, Peelen, and Smith 2005). Other methods include biotinylated lectin-neutravidin bridging (Angeloni et al. 2005), DNA-driven immobilization of lectins on polystyrene latex particles (Fromell et al. 2005), and binding to hydrogel based surfaces (Koshi et al. 2006). Unfortunately, no method can control for the optimal orientation of the CRD of lectins, to maximize the lectin binding ability and for the reproducibility of the assay. Techniques such as covalent bonding of lectins by carbenes have shown to 
immobilize the lectins but failed to preserve the carbohydrate binding activity (Angeloni et al. 2005) indicating the importance of preserving the CRD of lectins when lectin arrays are generated. The lack of control for lectin immobilization may lead to increased variation of assays. The variations of spotting have been reported to be 10-20\% (Kuno et al. 2005) and the variation of a reverse-phase dot-blot assay, 10\% (Patwa et al. 2006), which may be too high to qualify for FDA approval. To preserve the CRD, it has been suggested that glycans of glycosylated lectins may be used as an anchor point for attachment, followed by anchoring to hydroxylamine or hydrazine containing solid surface, which would preserve the CRD of the lectin (Gupta, Surolia, and Sampathkumar 2010). Of course, not all lectins are glycosylated, but this may help lower the variation of a biomarker assay. Additionally, the LAM type may be more suitable for phase 3 and above biomarker assays to avoid this issue. As in most protein arrays, binding is, in most cases, detected by fluorescence (Pilobello and Mahal 2007; Gemeiner et al. 2009) using fluophores such as Cy3/Cy5, Alexa Fluor 555, and phycoerythrin. A number of different technologies have been introduced to increase the sensitivity of detection and salvage weak lectin-glycan bonds. Kuno et al. have introduced the use of evanescent-field fluorescence which allows in situ detection without a washing step to wash away any unbound material (Kuno et al. 2005). However, this technique requires a specialized evanescent-field fluorescence scanner. Other methods proposed include a modified fluorescence resonance energy transfer (FRET) method which demonstrated that a biomolecular fluorescence quenching and recovery (BFQR) technique can be used together with a supramolecular hydrogel matrix for the selective recognition of lectin-glycan bonds in reverse-phase dot-blot assays (Koshi et al. 2006). The use of tyramide signal amplification (TSA), which is a horseradish peroxidase (HRP)-mediated signal amplification method for ALM, has also shown to enhance signaling and therefore, increase the sensitivity of ALM over 100 times and allowed the detection of weak lectin-glycan interactions as demonstrated with as low as $20 \mathrm{ng}$ of prostate specific antigen from seminal fluid (Meany et al. 2011).

\section{Conclusions}

There is no doubt that advancement in proteomics has and will contribute to protein biomarker discovery. Especially, technological advancement has enabled glyco-biomarker research. Medium to high abundance blood glycoproteins with disease-specific glycosylation structures are attractive as glyco-biomarkers, with potential for development of robust clinical assays compared to low abundance blood proteins. However, there is still a general lack of high-throughput glycoproteomics platforms to facilitate the discovery and validation of candidate glyco-biomarkers. The technologies and sample types used in the phases of glyco-biomarker discovery are critical to the final outcome, that is, development of a clinical assay.

In this chapter, we highlight the potential of lectins as a unifying glycan affinity tool for glyco-biomarker discovery. Lectin-based glycoprotein enrichment methods such as lectin affinity chromatography and high-throughput LeMBA can be coupled with LC-MS/MS to generate candidate biomarkers (phase 1 biomarker discovery). After the discovery of potential biomarkers, lectin affinity techniques such as LeMBA can be coupled to SRM-MS for high-throughput verification of a large number of patient samples. Finally, for phase 3 and onwards, ALM or LAM type lectin microarrays or lectin-coupled immunosorbent assays can be used for further validation of the biomarker assay to ensure high clinical and analytical performance. Having a unifying affinity reagent will improve the consistency and, therefore, success rate of transfer between the phases of biomarker discovery. 
Combined with the appropriate bioinformatics tools, such as the recently developed serum glycopeptide SRM atlas (Schiess, Wollscheid, and Aebersold 2009) and glycan databases (reviewed in Frank and Schloissnig 2010), glyco-biomarker discovery and validation will surely contribute to biomarker research.

\section{Acknowledgements}

MH is supported by Career Development Award No. 569512 from the National Health and Medical Research Council of Australia. EC is supported by the University of Queensland International Research Tuition Awards and the University of Queensland Research Scholarship. Development of LeMBA was supported by an Australian Animal Cancer Foundation grant and a University of Queensland Collaboration and Industry Engagement Fund. High-throughput proteomics sample preparation station for the University of Queensland Diamantina Institute was supported by a Ramaciotti Foundations Equipment Gift.

\section{References}

Abbott, K. L., and J. M. Pierce. 2010. "Lectin-based glycoproteomic techniques for the enrichment and identification of potential biomarkers." Methods Enzymol no. 480:461-76. doi: S0076-6879(10)80020-5 [pii] 10.1016/S0076-6879(10)80020-5.

Ahn, J. M., B. G. Kim, M. H. Yu, I. K. Lee, and J. Y. Cho. 2010. "Identification of diabetic nephropathy-selective proteins in human plasma by multi-lectin affinity chromatography and LC-MS/MS." Proteomics. Clinical applications no. 4 (6-7):644-53. doi: 10.1002/prca.200900196.

Albanell, J., F. Rojo, and J. Baselga. 2001. "Pharmacodynamic studies with the epidermal growth factor receptor tyrosine kinase inhibitor ZD1839." Semin Oncol no. 28 (5 Suppl 16):56-66. doi: asonc02805n0056 [pii].

Alhadeff, J. A., and R. T. Holzinger. 1982. "Sialyltransferase, sialic acid and sialoglycoconjugates in metastatic tumor and human liver tissue." The International journal of biochemistry no. 14 (2):119-26.

Alonzo, T. A., M. S. Pepe, and C. S. Moskowitz. 2002. "Sample size calculations for comparative studies of medical tests for detecting presence of disease." Stat Med no. 21 (6):835-52. doi: 10.1002/sim.1058 [pii].

Alvarez-Manilla, G., J. Atwood, 3rd, Y. Guo, N. L. Warren, R. Orlando, and M. Pierce. 2006. "Tools for glycoproteomic analysis: size exclusion chromatography facilitates identification of tryptic glycopeptides with N-linked glycosylation sites." J Proteome Res no. 5 (3):701-8. doi: 10.1021/pr050275j.

Alvarez-Manilla, G., N. L. Warren, J. Atwood, 3rd, R. Orlando, S. Dalton, and M. Pierce. 2010. "Glycoproteomic analysis of embryonic stem cells: identification of potential glycobiomarkers using lectin affinity chromatography of glycopeptides." Journal of Proteome Research no. 9 (5):2062-75. doi: 10.1021/pr8007489.

Anderson, L., and C. L. Hunter. 2006. "Quantitative mass spectrometric multiple reaction monitoring assays for major plasma proteins." Mol Cell Proteomics no. 5 (4):573-88. doi: M500331-MCP200 [pii] 10.1074/mcp.M500331-MCP200. 
Anderson, N. L., and N. G. Anderson. 2002. "The human plasma proteome: history, character, and diagnostic prospects." Mol Cell Proteomics no. 1 (11):845-67.

Angeloni, S., J.L. Ridet, N. Kusy, H. Gao, F. Crevoisier, S. Guinchard, S. Kochhar, H. Sigrist, and N. Sprenger. 2005. "Glycoprofiling with micro-arrays of glycoconjugates and lectins." Glycobiology no. 15 (1):31-41. doi: 10.1093/glycob/cwh143.

Bartels, C. L., and G. J. Tsongalis. 2009. "MicroRNAs: novel biomarkers for human cancer." Clin Chem no. 55 (4):623-31. doi: clinchem.2008.112805 [pii] 10.1373/clinchem.2008.112805.

Belda-Iniesta, C., J. de Castro, and R. Perona. 2011. "Translational proteomics: what can you do for true patients?" Journal of proteome research no. 10 (1):101-4. doi: 10.1021/pr100853a.

Boersema, P. J., R. Raijmakers, S. Lemeer, S. Mohammed, and A. J. Heck. 2009. "Multiplex peptide stable isotope dimethyl labeling for quantitative proteomics." Nature protocols no. 4 (4):484-94. doi: 10.1038/nprot.2009.21.

Boja, E., T. Hiltke, R. Rivers, C. Kinsinger, A. Rahbar, M. Mesri, and H. Rodriguez. 2011. "Evolution of clinical proteomics and its role in medicine." J Proteome Res no. 10 (1):66-84. doi: 10.1021/pr100532g.

Boja, E. S., and H. Rodriguez. 2011. "The path to clinical proteomics research: integration of proteomics, genomics, clinical laboratory and regulatory science." The Korean journal of laboratory medicine no. 31 (2):61-71. doi: 10.3343/ kjlm.2011.31.2.61.

Bones, J., S. Mittermayr, N. O'Donoghue, A. Guttman, and P. M. Rudd. 2010. "Ultra performance liquid chromatographic profiling of serum N-glycans for fast and efficient identification of cancer associated alterations in glycosylation." Analytical chemistry no. 82 (24):10208-15. doi: 10.1021/ac102860w.

Brooks, S. A., M. Lymboura, U. Schumacher, and A. J. Leathem. 1996. "Histochemistry to detect Helix pomatia lectin binding in breast cancer: methodology makes a difference." J Histochem Cytochem no. 44 (5):519-24.

Carter, T. M., and S. A. Brooks. 2006. "Detection of aberrant glycosylation in breast cancer using lectin histochemistry." Methods Mol Med no. 120:201-16.

Chen, X., L. Sun, Y. Yu, Y. Xue, and P. Yang. 2007. "Amino acid-coded tagging approaches in quantitative proteomics." Expert review of proteomics no. 4 (1):25-37. doi: 10.1586/14789450.4.1.25.

Comunale, M. A., M. Wang, J. Hafner, J. Krakover, L. Rodemich, B. Kopenhaver, R. E. Long, O. Junaidi, A. M. Bisceglie, T. M. Block, and A. S. Mehta. 2009. "Identification and development of fucosylated glycoproteins as biomarkers of primary hepatocellular carcinoma." J Proteome Res no. 8 (2):595-602. doi: 10.1021/pr800752c [pii].

Dayarathna, M. K., W. S. Hancock, and M. Hincapie. 2008. "A two step fractionation approach for plasma proteomics using immunodepletion of abundant proteins and multi-lectin affinity chromatography: Application to the analysis of obesity, diabetes, and hypertension diseases." J Sep Sci no. 31 (6-7):1156-66. doi: $10.1002 /$ jssc. 200700271.

de Leoz, M. L., L. J. Young, H. J. An, S. R. Kronewitter, J. Kim, S. Miyamoto, A. D. Borowsky, H. K. Chew, and C. B. Lebrilla. 2011. "High-mannose glycans are elevated during breast cancer progression." Mol Cell Proteomics no. 10 (1):M110 002717. doi: M110.002717 [pii] 10.1074/mcp.M110.002717. 
Drake, P. M., B. Schilling, R. K. Niles, M. Braten, E. Johansen, H. C. Liu, M. Lerch, D. J. Sorensen, B. S. Li, S. Allen, S. C. Hall, H. E. Witkowska, F. E. Regnier, B. W. Gibson, and S. J. Fisher. 2011. "A lectin affinity workflow targeting glycosite-specific, cancer-related carbohydrate structures in trypsin-digested human plasma." Analytical biochemistry no. 408 (1):71-85. doi: 10.1016/j.ab.2010.08.010.

Durham, M., and F. E. Regnier. 2006. "Targeted glycoproteomics: serial lectin affinity chromatography in the selection of O-glycosylation sites on proteins from the human blood proteome." J Chromatogr A no. 1132 (1-2):165-73. doi: S00219673(06)01467-1 [pii] 10.1016/j.chroma.2006.07.070.

Frank, M., and S. Schloissnig. 2010. "Bioinformatics and molecular modeling in glycobiology." Cellular and molecular life sciences : CMLS no. 67 (16):2749-72. doi: 10.1007/s00018-010-0352-4.

Fromell, K., M. Andersson, K. Elihn, and K. D. Caldwell. 2005. "Nanoparticle decorated surfaces with potential use in glycosylation analysis." Colloids and surfaces. B, Biointerfaces no. 46 (2):84-91. doi: 10.1016/j.colsurfb.2005.06.017.

Fujimura, T., Y. Shinohara, B. Tissot, P. C. Pang, M. Kurogochi, S. Saito, Y. Arai, M. Sadilek, K. Murayama, A. Dell, S. Nishimura, and S. I. Hakomori. 2008. "Glycosylation status of haptoglobin in sera of patients with prostate cancer vs. benign prostate disease or normal subjects." International journal of cancer. Journal international $d u$ cancer no. 122 (1):39-49. doi: 10.1002/ijc.22958.

Fung, E. T. 2010. "A recipe for proteomics diagnostic test development: the OVA1 test, from biomarker discovery to FDA clearance." Clinical chemistry no. 56 (2):327-9. doi: 10.1373/clinchem.2009.140855.

Gabrilovich, D. I. 2006. "INGN 201 (Advexin): adenoviral p53 gene therapy for cancer." Expert Opin Biol Ther no. 6 (8):823-32. doi: 10.1517/14712598.6.8.823.

Gemeiner, P., D. Mislovicova, J. Tkac, J. Svitel, V. Patoprsty, E. Hrabarova, G. Kogan, and T. Kozar. 2009. "Lectinomics II. A highway to biomedical/clinical diagnostics." Biotechnol Adv no. $27 \quad(1): 1-15$. doi: S0734-9750(08)00081-5 [pii] 10.1016/j.biotechadv.2008.07.003.

Gong, Y., X. Li, B. Yang, W. Ying, D. Li, Y. Zhang, S. Dai, Y. Cai, J. Wang, F. He, and X. Qian. 2006. "Different immunoaffinity fractionation strategies to characterize the human plasma proteome." Journal of proteome research no. 5 (6):1379-87. doi: $10.1021 /$ pr0600024.

Gray, J. W., and C. Collins. 2000. "Genome changes and gene expression in human solid tumors." Carcinogenesis no. 21 (3):443-52.

Green, E. D., R. M. Brodbeck, and J. U. Baenziger. 1987. "Lectin affinity high-performance liquid chromatography: interactions of N-glycanase-released oligosaccharides with leukoagglutinating phytohemagglutinin, concanavalin A, Datura stramonium agglutinin, and Vicia villosa agglutinin." Analytical biochemistry no. 167 (1):62-75.

Gupta, G., A. Surolia, and S. G. Sampathkumar. 2010. "Lectin microarrays for glycomic analysis." OMICS no. 14 (4):419-36. doi: 10.1089/omi.2009.0150.

Gutman, S., and L. G. Kessler. 2006. "The US Food and Drug Administration perspective on cancer biomarker development." Nat Rev Cancer no. 6 (7):565-71. doi: nrc1911 [pii] 10.1038/nrc1911. 
Hagglund, P., J. Bunkenborg, F. Elortza, O. N. Jensen, and P. Roepstorff. 2004. "A new strategy for identification of $\mathrm{N}$-glycosylated proteins and unambiguous assignment of their glycosylation sites using HILIC enrichment and partial deglycosylation." J Proteome Res no. 3 (3):556-66.

He, J., Y. Liu, X. Xie, T. Zhu, M. Soules, F. DiMeco, A. L. Vescovi, X. Fan, and D. M. Lubman. 2010. "Identification of cell surface glycoprotein markers for glioblastoma-derived stem-like cells using a lectin microarray and LC-MS/MS approach." Journal of proteome research no. 9 (5):2565-72. doi: 10.1021/pr100012p.

Hirabayashi, J. 2008. "Concept, strategy and realization of lectin-based glycan profiling." Journal of biochemistry no. 144 (2):139-47. doi: 10.1093/jb/mvn043.

Hudis, C. A. 2007. "Trastuzumab--mechanism of action and use in clinical practice." N Engl J Med no. 357 (1):39-51. doi: 357/1/39 [pii] 10.1056/ NEJMra043186.

Jung, K., W. Cho, and F. E. Regnier. 2009. "Glycoproteomics of plasma based on narrow selectivity lectin affinity chromatography." J Proteome Res no. 8 (2):643-50. doi: 10.1021/pr8007495 10.1021/pr8007495 [pii].

Katrlik, J., J. Svitel, P. Gemeiner, T. Kozar, and J. Tkac. 2010. "Glycan and lectin microarrays for glycomics and medicinal applications." Med Res Rev no. 30 (2):394-418. doi: 10.1002/med.20195.

Kobata, A., and T. Endo. 1992. "Immobilized Lectin Columns - Useful Tools for the Fractionation and Structural-Analysis of Oligosaccharides." Journal of Chromatography no. 597 (1-2):111-122.

Koshi, Y., E. Nakata, H. Yamane, and I. Hamachi. 2006. "A fluorescent lectin array using supramolecular hydrogel for simple detection and pattern profiling for various glycoconjugates." Journal of the American Chemical Society no. 128 (32):10413-22. doi: 10.1021/ja0613963.

Kulasingam, V., and E. P. Diamandis. 2008. "Strategies for discovering novel cancer biomarkers through utilization of emerging technologies." Nature clinical practice. Oncology no. 5 (10):588-99. doi: 10.1038/ncponc1187.

Kullolli, M., W. S. Hancock, and M. Hincapie. 2010. "Automated platform for fractionation of human plasma glycoproteome in clinical proteomics." Anal Chem no. 82 (1):11520. doi: $10.1021 /$ ac9013308.

Kuno, A., N. Uchiyama, S. Koseki-Kuno, Y. Ebe, S. Takashima, M. Yamada, and J. Hirabayashi. 2005. "Evanescent-field fluorescence-assisted lectin microarray: a new strategy for glycan profiling." Nature methods no. 2 (11):851-6. doi: $10.1038 /$ nmeth803.

Lau, P., J. L. Chin, S. Pautler, H. Razvi, and J. I. Izawa. 2009. "NMP22 is predictive of recurrence in high-risk superficial bladder cancer patients." Can Urol Assoc J no. 3 (6):454-8.

Lee, A., M. Nakano, M. Hincapie, D. Kolarich, M. S. Baker, W. S. Hancock, and N. H. Packer. 2010. "The lectin riddle: glycoproteins fractionated from complex mixtures have similar glycomic profiles." Omics : a journal of integrative biology no. 14 (4):487-99. doi: 10.1089/omi.2010.0075.

Li, C., D. M. Simeone, D. E. Brenner, M. A. Anderson, K. A. Shedden, M. T. Ruffin, and D. M. Lubman. 2009. "Pancreatic cancer serum detection using a lectin/glyco-antibody 
array method." J Proteome Res no. 8 (2):483-92. doi: 10.1021/pr8007013 $10.1021 /$ pr8007013 [pii].

Li, C., E. Zolotarevsky, I. Thompson, M. A. Anderson, D. M. Simeone, J. M. Casper, M. C. Mullenix, and D. M. Lubman. 2011. "A multiplexed bead assay for profiling glycosylation patterns on serum protein biomarkers of pancreatic cancer." Electrophoresis. doi: 10.1002/elps.201000693.

Lin, S. H., Y. C. Lee, G. Block, H. Chen, E. Folch-Puy, R. Foronjy, R. Jalili, C. B. Jendresen, M. Kimura, E. Kraft, S. Lindemose, J. Lu, T. McLain, L. Nutt, S. Ramon-Garcia, J. Smith, A. Spivak, M. L. Wang, and M. Zanic. 2008. "One-step isolation of plasma membrane proteins using magnetic beads with immobilized concanavalin A." Protein Expression and Purification no. 62 (2):223-229. doi: 10.1016/j.pep.2008.08.003.

Liu, Y., J. He, C. Li, R. Benitez, S. Fu, J. Marrero, and D. M. Lubman. 2010. "Identification and confirmation of biomarkers using an integrated platform for quantitative analysis of glycoproteins and their glycosylations." Journal of proteome research no. 9 (2):798805. doi: 10.1021/pr900715p.

Loo, D., A. Jones, and M. M. Hill. 2010. "Lectin magnetic bead array for biomarker discovery." J Proteome Res. doi: 10.1021/pr100472z.

Ludwig, J. A., and J. N. Weinstein. 2005. "Biomarkers in cancer staging, prognosis and treatment selection." Nat Rev Cancer no. 5 (11):845-56. doi: nrc1739 [pii] $10.1038 /$ nrc1739.

Manolio, T. A., J. E. Bailey-Wilson, and F. S. Collins. 2006. "Genes, environment and the value of prospective cohort studies." Nat Rev Genet no. 7 (10):812-20. doi: nrg1919 [pii] 10.1038/nrg1919.

Martens, L. 2011a. "Bioinformatics challenges in mass spectrometry-driven proteomics." Methods in molecular biology no. 753:359-71. doi: 10.1007/978-1-61779-148-2_24.

Martens, L. 2011b. "Data management in mass spectrometry-based proteomics." Methods in molecular biology no. 728:321-32. doi: 10.1007/978-1-61779-068-3_21.

Masuda, Tomomi, and Eiji Miyoshi. 2011. "Cancer biomarkers for hepatocellular carcinomas: from traditional markers to recent topics." Clinical Chemistry and Laboratory Medicine no. 49 (6):959-966. doi: 10.1515/cclm.2011.152.

McDonald, C. A., J. Y. Yang, V. Marathe, T. Y. Yen and Macher, B. A. 2009. "Combining Results from Lectin Affinity Chromatography and Glycocapture Approaches Substantially Improves the Coverage of the Glycoproteome." Molecular E Cellular Proteomics no. 8 (2):287-301. doi: 10.1074/mcp.M800272-MCP200.

Meany, D. L., L. Hackler, Jr., H. Zhang, and D. W. Chan. 2011. "Tyramide signal amplification for antibody-overlay lectin microarray: a strategy to improve the sensitivity of targeted glycan profiling." Journal of proteome research no. 10 (3):142531. doi: $10.1021 /$ pr1010873.

Meany, D. L., L. J. Sokoll, and D. W. Chan. 2009. "Early Detection of Cancer: Immunoassays for Plasma Tumor Markers." Expert opinion on medical diagnostics no. 3 (6):597-605. doi: 10.1517/17530050903266830.

Meany, Danni, and Daniel Chan. 2011. "Aberrant glycosylation associated with enzymes as cancer biomarkers." Clinical Proteomics no. 8 (1):7. 
Mechref, Y., M. Madera, and M. V. Novotny. 2008. "Glycoprotein enrichment through lectin affinity techniques." Methods Mol Biol no. 424:373-96. doi: 10.1007/978-1-60327-0649_29.

Mischak, H., R. Apweiler, R. E. Banks, M. Conaway, J. Coon, A. Dominiczak, J. H. H. Ehrich, D. Fliser, M. Girolami, H. Hermjakob, D. Hochstrasser, J. Jankowski, B. A. Julian, W. Kolch, Z. A. Massy, C. Neusuess, J. Novak, K. Peter, K. Rossing, J. Schanstra, O. J. Semmes, D. Theodorescu, V. Thongboonkerd, E. M. Weissinger, J. E. Van Eyk, and T. Yamamoto. 2007. "Clinical proteomics: A need to define the field and to begin to set adequate standards." Proteomics Clinical Applications no. 1 (2):148-156. doi: DOI 10.1002/prca.200600771.

Mishra, A., A. C. Bharti, P. Varghese, D. Saluja, and B. C. Das. 2006. "Differential expression and activation of NF-kappaB family proteins during oral carcinogenesis: Role of high risk human papillomavirus infection." Int J Cancer no. 119 (12):2840-50. doi: 10.1002/ijc.22262.

Mishra, Alok, and Mukesh Verma. 2010. "Cancer Biomarkers: Are We Ready for the Prime Time?" Cancers no. 2 (1):190-208.

Na, K., E. Y. Lee, H. J. Lee, K. Y. Kim, H. Lee, S. K. Jeong, A. S. Jeong, S. Y. Cho, S. A. Kim, S. Y. Song, K. S. Kim, S. W. Cho, H. Kim, and Y. K. Paik. 2009. "Human plasma carboxylesterase 1, a novel serologic biomarker candidate for hepatocellular carcinoma." Proteomics no. 9 (16):3989-99. doi: 10.1002/pmic.200900105.

Negm, R. S., M. Verma, and S. Srivastava. 2002. "The promise of biomarkers in cancer screening and detection." Trends Mol Med no. 8 (6):288-93. doi: S1471491402023535.

Osterfeld, Sebastian J., Heng Yu, Richard S. Gaster, Stefano Caramuta, Liang Xu, Shu-Jen Han, Drew A. Hall, Robert J. Wilson, Shouheng Sun, Robert L. White, Ronald W. Davis, Nader Pourmand, and Shan X. Wang. 2008. "Multiplex protein assays based on real-time magnetic nanotag sensing." Proceedings of the National Academy of Sciences no. 105 (52):20637-20640. doi: 10.1073/pnas.0810822105.

Packer, N. H., C. W. von der Lieth, K. F. Aoki-Kinoshita, C. B. Lebrilla, J. C. Paulson, R. Raman, P. Rudd, R. Sasisekharan, N. Taniguchi, and W. S. York. 2008. "Frontiers in glycomics: bioinformatics and biomarkers in disease. An NIH white paper prepared from discussions by the focus groups at a workshop on the NIH campus, Bethesda MD (September 11-13, 2006)." Proteomics no. 8 (1):8-20. doi: 10.1002/pmic.200700917.

Pan, S., R. Chen, R. Aebersold, and T. A. Brentnall. 2011. "Mass spectrometry based glycoproteomics--from a proteomics perspective." Mol Cell Proteomics no. 10 (1):R110 003251. doi: R110.003251 [pii] 10.1074/mcp.R110.003251.

Patwa, Tasneem H., Jia Zhao, Michelle A. Anderson, Diane M. Simeone, and David M. Lubman. 2006. "Screening of Glycosylation Patterns in Serum Using Natural Glycoprotein Microarrays and Multi-Lectin Fluorescence Detection." Analytical chemistry no. 78 (18):6411-6421. doi: 10.1021/ac060726z.

Pepe, M. S., R. Etzioni, Z. Feng, J. D. Potter, M. L. Thompson, M. Thornquist, M. Winget, and Y. Yasui. 2001. "Phases of biomarker development for early detection of cancer." J Natl Cancer Inst no. 93 (14):1054-61.

Pilobello, K. T., and L. K. Mahal. 2007. "Lectin microarrays for glycoprotein analysis." Methods in molecular biology no. 385:193-203. 
Plavina, T., E. Wakshull, W. S. Hancock, and M. Hincapie. 2007. "Combination of abundant protein depletion and multi-lectin affinity chromatography (M-LAC) for plasma protein biomarker discovery." Journal of proteome research no. 6 (2):662-71. doi: $10.1021 /$ pr060413k.

Polanski, M., and N. L. Anderson. 2007. "A list of candidate cancer biomarkers for targeted proteomics." Biomark Insights no. 1:1-48.

Qiu, Y., T. H. Patwa, L. Xu, K. Shedden, D. E. Misek, M. Tuck, G. Jin, M. T. Ruffin, D. K. Turgeon, S. Synal, R. Bresalier, N. Marcon, D. E. Brenner, and D. M. Lubman. 2008. "Plasma glycoprotein profiling for colorectal cancer biomarker identification by lectin glycoarray and lectin blot." J Proteome Res no. 7 (4):1693-703. doi: $10.1021 /$ pr700706s.

Rakus, J. F., and L. K. Mahal. 2011. "New technologies for glycomic analysis: toward a systematic understanding of the glycome." Annual review of analytical chemistry no. 4 (1):367-92. doi: 10.1146/annurev-anchem-061010-113951.

Ray, S., P. J. Reddy, S. Choudhary, D. Raghu, and S. Srivastava. 2011. "Emerging nanoproteomics approaches for disease biomarker detection: A current perspective." Journal of proteomics. doi: 10.1016/j.jprot.2011.04.027.

Rifai, N., M. A. Gillette, and S. A. Carr. 2006. "Protein biomarker discovery and validation: the long and uncertain path to clinical utility." Nat Biotechnol no. 24 (8):971-83. doi: nbt1235 [pii] 10.1038/nbt1235.

Roses, R. E., E. C. Paulson, A. Sharma, J. E. Schueller, H. Nisenbaum, S. Weinstein, K. R. Fox, P. J. Zhang, and B. J. Czerniecki. 2009. "HER-2/neu overexpression as a predictor for the transition from in situ to invasive breast cancer." Cancer Epidemiol Biomarkers Prev no. 18 (5):1386-9. doi: 1055-9965.EPI-08-1101 [pii] 10.1158/1055-9965.EPI-081101.

Schiess, Ralph, Bernd Wollscheid, and Ruedi Aebersold. 2009. "Targeted proteomic strategy for clinical biomarker discovery." Molecular Oncology no. 3 (1):33-44. doi: 10.1016/j.molonc.2008.12.001.

Shamberger, R. J. 1984. "Serum sialic acid in normals and in cancer patients." Journal of clinical chemistry and clinical biochemistry. Zeitschrift fur klinische Chemie und klinische Biochemie no. 22 (10):647-51.

Silver, H. K., K. A. Karim, E. L. Archibald, and F. A. Salinas. 1979. "Serum sialic acid and sialyltransferase as monitors of tumor burden in malignant melanoma patients." Cancer research no. 39 (12):5036-42.

Smith, M. P., S. L. Wood, A. Zougman, J. T. Ho, J. Peng, D. Jackson, D. A. Cairns, A. J. Lewington, P. J. Selby, and R. E. Banks. 2011. "A systematic analysis of the effects of increasing degrees of serum immunodepletion in terms of depth of coverage and other key aspects in top-down and bottom-up proteomic analyses." Proteomics no. 11 (11):2222-35. doi: 10.1002/pmic.201100005.

Sparbier, K., T. Wenzel, and M. Kostrzewa. 2006. "Exploring the binding profiles of ConA, boronic acid and WGA by MALDI-TOF/TOF MS and magnetic particles." J Chromatogr B Analyt Technol Biomed Life Sci no. 840 (1):29-36. doi: S15700232(06)00526-5 [pii] 10.1016/j.jchromb.2006.06.028.

Srivastava, S., and R. Gopal-Srivastava. 2002. "Biomarkers in cancer screening: a public health perspective." J Nutr no. 132 (8 Suppl):2471S-2475S. 
Srivastava, S., M. Verma, and R. Gopal-Srivastava. 2005. "Proteomic maps of the cancerassociated infectious agents." J Proteome Res no. 4 (4):1171-80. doi: 10.1021/pr050017m.

Sturgeon, C. M., M. J. Duffy, B. R. Hofmann, R. Lamerz, H. A. Fritsche, K. Gaarenstroom, J. Bonfrer, T. H. Ecke, H. B. Grossman, P. Hayes, R. T. Hoffmann, S. P. Lerner, F. Lohe, J. Louhimo, I. Sawczuk, K. Taketa, and E. P. Diamandis. 2010. "National Academy of Clinical Biochemistry Laboratory Medicine Practice Guidelines for use of tumor markers in liver, bladder, cervical, and gastric cancers." Clin Chem no. 56 (6):e1-48. doi: clinchem.2009.133124 [pii] 10.1373/clinchem.2009.133124.

Sturgeon, C. M., M. J. Duffy, U. H. Stenman, H. Lilja, N. Brunner, D. W. Chan, R. Babaian, R. C. Bast, Jr., B. Dowell, F. J. Esteva, C. Haglund, N. Harbeck, D. F. Hayes, M. HoltenAndersen, G. G. Klee, R. Lamerz, L. H. Looijenga, R. Molina, H. J. Nielsen, H. Rittenhouse, A. Semjonow, M. Shih Ie, P. Sibley, G. Soletormos, C. Stephan, L. Sokoll, B. R. Hoffman, and E. P. Diamandis. 2008. "National Academy of Clinical Biochemistry laboratory medicine practice guidelines for use of tumor markers in testicular, prostate, colorectal, breast, and ovarian cancers." Clin Chem no. 54 (12):e11-79. doi: 54/12/e11 [pii] 10.1373/clinchem.2008.105601.

Sun, B., J. A. Ranish, A. G. Utleg, J. T. White, X. Yan, B. Lin, and L. Hood. 2007. "Shotgun glycopeptide capture approach coupled with mass spectrometry for comprehensive glycoproteomics." Mol Cell Proteomics no. 6 (1):141-9. doi: T600046MCP200 [pii] 10.1074/mcp.T600046-MCP200.

Surinova, S., R. Schiess, R. Huttenhain, F. Cerciello, B. Wollscheid, and R. Aebersold. 2011. "On the development of plasma protein biomarkers." J Proteome Res no. 10 (1):5-16. doi: $10.1021 /$ pr1008515.

Theilacker, Nora, Eric E. Roller, Kristopher D. Barbee, Matthias Franzreb, and Xiaohua Huang. 2011. "Multiplexed protein analysis using encoded antibody-conjugated microbeads." Journal of The Royal Society Interface no. 8 (61):1104-1113. doi: 10.1098/rsif.2010.0594.

Tousi, Fateme, William S. Hancock, and Marina Hincapie. 2011. "Technologies and strategies for glycoproteomics and glycomics and their application to clinical biomarker research." Analytical Methods no. 3 (1):20-32.

Tu, C., P. A. Rudnick, M. Y. Martinez, K. L. Cheek, S. E. Stein, R. J. Slebos, and D. C. Liebler. 2010. "Depletion of abundant plasma proteins and limitations of plasma proteomics." Journal of proteome research no. 9 (10):4982-91. doi: 10.1021/pr100646w.

Verma, M., and U. Manne. 2006. "Genetic and epigenetic biomarkers in cancer diagnosis and identifying high risk populations." Crit Rev Oncol Hematol no. 60 (1):9-18. doi: S1040-8428(06)00087-4 [pii] 10.1016/j.critrevonc.2006.04.002.

Wang, P., J. R. Whiteaker, and A. G. Paulovich. 2009. "The evolving role of mass spectrometry in cancer biomarker discovery." Cancer Biol Ther no. 8 (12):1083-94. doi: 8634 [pii].

Welinder, C., B. Jansson, M. Ferno, H. Olson, and B. Baldetorp. 2009. "Expression of Helix pomatia lectin binding glycoproteins in women with breast cancer in relationship to their blood group phenotypes." J Proteome Res no. 8 (2):782-7. doi: 10.1021/pr800444b. 
West, I., and O. Goldring. 1996. "Lectin affinity chromatography." Methods in molecular biology no. 59:177-85. doi: 10.1385/0-89603-336-8:177.

Xu, Z., X. Zhou, H. Lu, N. Wu, H. Zhao, L. Zhang, W. Zhang, Y. L. Liang, L. Wang, Y. Liu, P. Yang, and X. Zha. 2007. "Comparative glycoproteomics based on lectins affinity capture of N-linked glycoproteins from human Chang liver cells and MHCC97-H cells." Proteomics no. 7 (14):2358-70. doi: 10.1002/pmic.200600041.

Yang, N., S. Feng, K. Shedden, X. L. Xie, Y. S. Liu, C. J. Rosser, D. M. Lubman, and S. Goodison. 2011. "Urinary Glycoprotein Biomarker Discovery for Bladder Cancer Detection Using LC/MS-MS and Label-Free Quantification." Clinical Cancer Research no. 17 (10):3349-3359. doi: 10.1158/1078-0432.CCR-10-3121.

Yang, Z., and W. S. Hancock. 2004. "Approach to the comprehensive analysis of glycoproteins isolated from human serum using a multi-lectin affinity column." $J$ Chromatogr A no. 1053 (1-2):79-88.

Yang, Z., and W. S. Hancock. 2004. "Approach to the comprehensive analysis of glycoproteins isolated from human serum using a multi-lectin affinity column." $J$ Chromatogr A no. 1053 (1-2):79-88.

Yang, Z., L. E. Harris, D. E. Palmer-Toy, and W. S. Hancock. 2006. "Multilectin affinity chromatography for characterization of multiple glycoprotein biomarker candidates in serum from breast cancer patients." Clin Chem no. 52 (10):1897-905. doi: clinchem.2005.065862 [pii] 10.1373/clinchem.2005.065862.

Yoon, S. J., S. Y. Park, P. C. Pang, J. Gallagher, J. E. Gottesman, A. Dell, J. H. Kim, and S. I. Hakomori. 2010. "N-glycosylation status of beta-haptoglobin in sera of patients with prostate cancer vs. benign prostate diseases." Int J Oncol no. 36 (1):193-203.

Zeng, Z., M. Hincapie, S. J. Pitteri, S. Hanash, J. Schalkwijk, J. M. Hogan, H. Wang, and W. S. Hancock. 2011. "A proteomics platform combining depletion, multi-lectin affinity chromatography (M-LAC), and isoelectric focusing to study the breast cancer proteome." Analytical chemistry no. 83 (12):4845-54. doi: 10.1021/ac2002802.

Zhang, H., X. J. Li, D. B. Martin, and R. Aebersold. 2003. “Identification and quantification of N-linked glycoproteins using hydrazide chemistry, stable isotope labeling and mass spectrometry." Nature biotechnology no. 21 (6):660-6. doi: 10.1038/nbt827.

Zhang, Q., V. Faca, and S. Hanash. 2011. "Mining the plasma proteome for disease applications across seven logs of protein abundance." J Proteome Res no. 10 (1):46-50. doi: 10.1021/pr101052y.

Zhao, J., T. H. Patwa, W. Qiu, K. Shedden, R. Hinderer, D. E. Misek, M. A. Anderson, D. M. Simeone, and D. M. Lubman. 2007. "Glycoprotein microarrays with multi-lectin detection: unique lectin binding patterns as a tool for classifying normal, chronic pancreatitis and pancreatic cancer sera." Journal of proteome research no. 6 (5):1864-74. doi: $10.1021 /$ pr070062p.

Zhao, J., D. M. Simeone, D. Heidt, M. A. Anderson, and D. M. Lubman. 2006. "Comparative serum glycoproteomics using lectin selected sialic acid glycoproteins with mass spectrometric analysis: application to pancreatic cancer serum." J Proteome Res no. 5 (7):1792-802. doi: 10.1021/pr060034r.

Zheng, T., D. Peelen, and L. M. Smith. 2005. "Lectin arrays for profiling cell surface carbohydrate expression." Journal of the American Chemical Society no. 127 (28):99823. doi: 10.1021/ja0505550. 
Zielinska, D. F., F. Gnad, J. R. Wisniewski, and M. Mann. 2010. "Precision mapping of an in vivo N-glycoproteome reveals rigid topological and sequence constraints." Cell no. 141 (5):897-907. doi: 10.1016/j.cell.2010.04.012. 


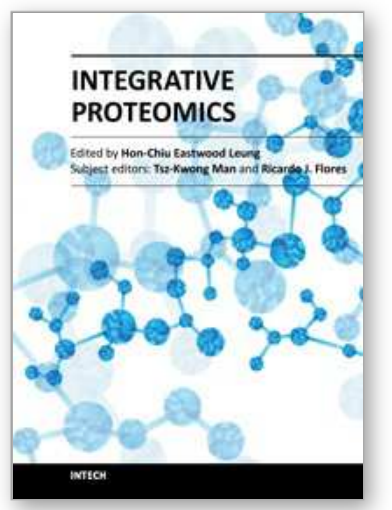

\author{
Integrative Proteomics \\ Edited by Dr. Hon-Chiu Leung
}

ISBN 978-953-51-0070-6

Hard cover, 442 pages

Publisher InTech

Published online 24, February, 2012

Published in print edition February, 2012

Proteomics was thought to be a natural extension after the field of genomics has deposited significant amount of data. However, simply taking a straight verbatim approach to catalog all proteins in all tissues of different organisms is not viable. Researchers may need to focus on the perspectives of proteomics that are essential to the functional outcome of the cells. In Integrative Proteomics, expert researchers contribute both historical perspectives, new developments in sample preparation, gel-based and non-gel-based protein separation and identification using mass spectrometry. Substantial chapters are describing studies of the sub-proteomes such as phosphoproteome or glycoproteomes which are directly related to functional outcomes of the cells. Structural proteomics related to pharmaceutics development is also a perspective of the essence.

Bioinformatics tools that can mine proteomics data and lead to pathway analyses become an integral part of proteomics. Integrative proteomics covers both look-backs and look-outs of proteomics. It is an ideal reference for students, new researchers, and experienced scientists who want to get an overview or insights into new development of the proteomics field.

\title{
How to reference
}

In order to correctly reference this scholarly work, feel free to copy and paste the following:

Eunju Choi and Michelle M. Hill (2012). Targeted High-Throughput Glycoproteomics for Glyco-Biomarker Discovery, Integrative Proteomics, Dr. Hon-Chiu Leung (Ed.), ISBN: 978-953-51-0070-6, InTech, Available from: http://www.intechopen.com/books/integrative-proteomics/targeted-high-throughput-glycoproteomics-forglyco-biomarker-discovery

\section{INTECH}

open science | open minds

\section{InTech Europe}

University Campus STeP Ri Slavka Krautzeka 83/A 51000 Rijeka, Croatia Phone: +385 (51) 770447 Fax: +385 (51) 686166 www.intechopen.com

\section{InTech China}

Unit 405, Office Block, Hotel Equatorial Shanghai

No.65, Yan An Road (West), Shanghai, 200040, China 中国上海市延安西路65号上海国际贵都大饭店办公楼 405 单元

Phone: +86-21-62489820

Fax: +86-21-62489821 
(C) 2012 The Author(s). Licensee IntechOpen. This is an open access article distributed under the terms of the Creative Commons Attribution 3.0 License, which permits unrestricted use, distribution, and reproduction in any medium, provided the original work is properly cited. 